\title{
Understanding Goal Ontology Model to Achieve Organization Goal Conformance
}

\author{
Tengku Adil Tengku Izhar \\ Faculty of Information Management, \\ Universiti Teknology MARA, \\ UiTM Selangor, Malaysia \\ Trieu Minh Nhut Le \\ Department of Computer Science and Computer Engineering, \\ Saigon University, \\ Ho Chi Minh City, Vietnam
}

Received: January 16, 2020 Accepted: February 20, $2021 \quad$ Published: March 11, 2021

doi:10.5296/ijssr.v9i1.18398 URL: https://doi.org/10.5296/ijssr.v9i1.18398

\begin{abstract}
This paper proposes a modelling concept for the organizational goals as a tool to evaluate organization data conformance to achieve the organization goal. This refer to the important in assisting the organization to utilize the organization data and information from the vast amount of data for decision making which will be in line with the organization's goals. The paper has two aims. The first aim is to develop a model based on organizational goal elements such as the main goal, sub-goals, actions and tasks. A formal ontology is developed to specific role between the organization goal elements. The second aim is to develop a metric model to interpret organization data in relation to the organization's goal. We apply a case study to evaluate our model development and metric development. Overall contribution of this paper is to propose a conceptual model that seeks to support the evaluation of organization data based on organization goal elements in the achievement of the organization's goals.
\end{abstract}

Keywords: action, data, data usage, goals, goal tree model, metric, organization, ontology, sub-goal, task 


\section{Introduction}

Data are important and valuable resource that supports managerial decision making in daily business activities. In organization, the amount of data continues to grow and information technology also has changed beyond storage, transmission and processing (Seng \& Chen, 2010). At the same time, professionals are trained to analyse organization data but the increase in the amount of organization data has become a major problem in applying these data because they do not have enough accurate and reliable data to assist the reliability decision making. Even though the organization has a vast amount of data but at the same time, they do not have the data that they really need. Thus, the trustworthiness of organization data in relation to meeting the organization goals is questioned and it create an issue on how to optimum the selected data be used for better decision making and achieving excellent organization's goals.

Previous research in this area has mainly looked at this issue from data processes point of view that addresses either software development or data mining, both of which are beyond the scope. Most studies which have been conducted in this issue focus on data mining or knowledge discovery in databases (KDD). KDD is an interdisciplinary field that searches for valuable information in large volumes of data and has played an important role in identifying effective patterns from a vast amount of data (Lee et al., 2008). On the other hand, the quality of organization data is important in order to improve decision making. Past studies have discussed the concept of quality metrics as an approach for data analysis (Albino et al., 2001; Ebert \& Morschel, 1997; Hevner, 1997; Ordonez \& Garcia-Garcia, 2008; Petkova et al., 2000). For example, the Goal Question Metric (GQM) discussed in (Ardimento et al., 2006; Basili \& Weiss, 1984), is a general methodology for the development of the quality metric approach. Another example is business intelligence (BI). BI is a computer-based technique to analyse business data which provide past and current of business strategies and business operation for decision making. BI has been practiced toward competitive intelligence where BI aims to support better decision-making process based on past and current business strategies. Based on these three approaches, we conclude these approaches are between data and process. We come out with this conclusion because, first, KDD is a concept identifying new knowledge in the field of computer science that describes the process of searching a vast amount of data in order to produce knowledge. However, KDD applies the concept within the system instead of searching and evaluating organization data. Second, GQM is a metric approach for software to develop a measurement model. GQM is applied for software industry in order to integrate software measurement model. Thus, GQM is an approach toward processes and process is very dynamic where it is difficult to handle because processes constantly change based on the environment. Third, BI aims to analyse business data by providing past and current data as a strategy to assist decision making. BI analyses data for business strategies instead of evaluating the degree to which the retrieval of relevant data assist the organization to achieve its organizational goals. While many studies have looked at the process of data collection, we move the literature a step ahead by developing a conceptual model which can incorporate the organization data and can lead to the reliability decision making in meeting the organization's goals. 


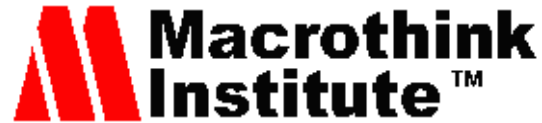

The aim of this paper is to develop an ontology model and metric model in the context of the organization's goals. In this paper, we propose these models as a tool to evaluate the quality of organization data in order to support managerial decision making and thereby assist the organization to achieve its goals. We suggest that these models are important in an effort to evaluate the quality and relevant organization data. At the meantime, these models are important in measuring the extent that organization data are consistent with the organization goal. In the present paper, we identify organizational goal elements such as the organization's goals, sub-goals, actions and tasks and we identify a relationship between these elements using ontology.

The remainder of this paper is organized as following. In Section 2, we introduce our model within the organization goal context. Relevant existing literature is introduced to support the model in an effort to identify the organizational goal elements. In Section 3, we develop our conceptual model. In this section, we develop the model based on ontology and we develop a metric model in order to evaluate organization data. The ontology model highlights the dependency relationship between the organizational goal elements. In Section 4, we apply a case study. In this case study, we use library data and we apply our metric model to interpret library data. The aim of this case study is to demonstrate the feasibility of our concept for applied work. Section 5 is a discussion and the final section contains concluding remarks and future works.

\section{Literature Review}

In this section, we outline existing literature prior to proposing our model. The discussion includes a comparison of ontology literature, organizational goals and current issues of managing organization data. Recently, the development of a business process to integrate business strategies and knowledge management has been widely discussed topic. In contrast to past studies, we develop a model to evaluate organization data by identifying the organization's goal elements. In this section, we provide a detailed literature review to compare the previous approaches which are relevant to our topic in order to identify the gaps in the existing research in relation to organizational goals and goal setting.

\subsection{Ontology Literature}

The existing literature on ontology approaches addresses either software development or data mining, both of which are beyond the scope of this paper. However, the most important work on ontology development is briefly discussed in this section to identify the existing gaps in the current research.

In organizations, it is important to use data and information to predict future performance. Information needs to be readily retrievable. Jimeno-Yepes et al. (2010) studied on ontology refinement to improve information retrieval. In this study, the authors used an ontology query model to analyse the usefulness of the ontology in effectively performing document searches. In our work, we use an ontology to identify the relationships between organizational goal elements in an effort to evaluate organization data.

In order to survive in today's competitive environment, most enterprises recognize the 
importance of their knowledge assets in achieving performance goals. However, when knowledge is separated from the context of the business process, it cannot contribute to performance goals (Han \& Park, 2009). In this study, the authors proposed a knowledge model framework and an enterprise ontology for a process-centered enterprise structure by classifying the model into two types: process knowledge and task support knowledge. Our work is similar to the work of (Han \& Park, 2009) in terms of enterprise ontology development to gain new knowledge, but we focus on organization data evaluation instead of the process of knowledge creation.

Table 1. Ontology approach and concept

\begin{tabular}{|c|c|c|}
\hline Authors & Approach & Conceptual \\
\hline Kang et al., 2010a & $\begin{array}{l}\text { - Ontology enterprise architecture } \\
\text { - Zachman's enterprise architecture } \\
\text { framework }\end{array}$ & $\begin{array}{l}\text { Development of a business process to } \\
\text { enhance the business environment. }\end{array}$ \\
\hline Kang et al., 2010b & $\begin{array}{ll}\text { - } & \text { Fact based enterprise ontology } \\
\text { - } & \text { Enterprise meta model } \\
\text { - } & \text { Enterprise architecture }\end{array}$ & $\begin{array}{l}\text { Measuring organization resource for } \\
\text { enterprise process and strategy. }\end{array}$ \\
\hline Han and Park, 2009 & $\begin{array}{ll}\text { - } & \text { Enterprise ontology } \\
\text { - } & \text { KMS }\end{array}$ & Knowledge on enterprise performance. \\
\hline $\begin{array}{l}\text { Jimeno-Yepes et al., } \\
2010\end{array}$ & - Ontology refinement & $\begin{array}{l}\text { Data usage and information retrieval to } \\
\text { enhance enterprise performance. }\end{array}$ \\
\hline Huang and Diao, 2008 & $\begin{array}{ll}\text { - } & \text { Ontology } \\
\text { - } & \text { Semantic Web Rule language } \\
\end{array}$ & $\begin{array}{l}\text { Managing enterprise knowledge during } \\
\text { the business process. }\end{array}$ \\
\hline
\end{tabular}

Table 1 lists various approaches in previous studies and shows that most focus on the development of an enterprise ontology which is similar to our goal. For example, Kang et al. (2010a) examined the relationship between business systems and the staff within an organization in order to better understand the communication problems which hinder collaborations with other organizations. The authors developed an ontology based on enterprise architecture. Another example of enterprise architecture was proposed by Kang et al. (2010b) who developed an enterprise ontology to support enterprise strategies. In this study, they looked at the organization's resources that support enterprise processes based on the organization's strategies. Han and Park (2009) studied business processes in relation to a knowledge management system as knowledge is a critical driving force in relation to the organization achieving its performance goals. In this study, they investigated if knowledge was separated from the business process hence hindering the target performance. Jimeno-Yepes et al. (2010) studied ontologies in information retrieval (IR). In this study, the authors examined whether ontology resources appeared in IR either to perform semantic indexing of documents or to produce a better organization of retrieved documents. Lastly, Huang and Diao (2008) studied knowledge integration using ontologies. In this study, an ontology becomes an important concept for knowledge integration where enterprises are 
getting more knowledge intensive with the development of various types of knowledge within organizations. Our work is similar to that of (Kang et al., 2010a; Han \& Park, 2009; Jimeno-Yepes et al., 2010) in terms of ontology development within an enterprise. However, our work can be seen to be a quality model by focusing on organization data evaluation within the context of the organization's goals.

\subsection{Organizational Goals}

Barlas and Yasarcan (2006) provided a model for goal setting in order to support an organization's performance. In this study, the organization's performance level is evaluated in relation to the organization's goals, and, in return, the effectiveness of the goal should be evaluated also. Studies on organization's goals have been conducted since the 1970s. In addition, the identification of variables was first studied in 1973 by England and Lee (1973). They studied the influence on perceiving organizational goal. In this study, the authors identified several variables in order to represent a relatively diverse group for organization's goal. This study was supported by Lusk and Oliver (1974), who focused on the social goals involved in the achievement of the overall organizational goal. On the other hand, Hall and Hall (1976) identified several variables in order to study the relationship between various organization goal. In this study, the authors investigated the relationship between goals, performance, success, self-image, involvement and future goals. A recent study by Ceresia (2011) proposed a model for the development of dynamic goals within the organization. The authors focused on the systematic dynamic for goal rather than analysing the usage of data in the achievement of organizational goal. This paper is less focussed on the goal process as discussed in (Lusk \& Oliver, 1974; Hall \& Hall, 1976; Ceresia, 2011), rather, our work evaluates organization data which is in line with organization goals. Our work evaluates the degree to which the validity of quality organization data in the achievement of the organization's goals.

\subsection{Current Issues of Managing Organization Data}

Entrepreneurship is an important aspect in economic development and wealth creation (Song et al., 2010; Christensen \& Bower, 1996). However, many new entrepreneurs are failed to identify the quality of organization data which can lead to poor decisions in relation to the organization's finance. A previous empirical study on new U.S technology ventures found that after four years, only $36 \%$ of companies survived and after one more year, the survival rate decreased to $21.9 \%$ (Song et al., 2008). Bad management in terms of the collection of information and subsequent poor planning based on this information is one explanation for this failure (Gruber, 2007). In the real business world, collecting high quality information and formulating a suitable business plan based on this information is crucial as entrepreneurs rely on organization data to assist in decision making. Thus, it is important for entrepreneurs to collect data that can improve their decision making.

This section discussed past studies which focused on enterprise's ontologies, in similar way to this paper, but none of the previous studies focus on ontology development in relation to the organizational goals. In this paper, we identify organizational goal elements to develop an organizational goal ontology. Many studies on data evaluation have been conducted but little 
research has been directed to the evaluation of organization data in the achievement of the organization's goals. Past studies discussed organizational goals but none evaluated the quality of the organization data in relation to meeting the organization goal. The studies are more on process toward data instead of measuring directly on organization data. These are the gaps in the existing literature have been identified and our aim in this paper is to develop a model in an effort to evaluate the degree to which the retrieval of relevant and quality organization data assists the organization to achieve its organizational goals.

\section{Methodology}

This section consists of two main aims. The first aim is to develop a model based on ontology. The second aim is to develop a metric model. We expand the models with the basic terminologies.

\subsection{Ontology Model}

In this subsection, we briefly develop an ontology model based on Org goal $_{\text {gal }}$ elements. First, we identify organizational goal elements. The elements are the organization's goals, sub-goals, actions and tasks. To make to discussion as clear as possible, we use AND/OR tree model as an example. In the rest of this paper, we denote organization goal as $\operatorname{Org}_{\text {goal }}$, sub-goal as $S u b_{\text {goal }}$, action as $A_{\text {ction }}$ and task as $T_{a s k}$. Then, we identify the roles between $\operatorname{Org}_{\text {goal }}$ elements based on ontology.

\subsubsection{Basic Terminologies}

In this subsection, we introduce the terminologies of Org goal $_{\text {gal }}$ elements based on the ontology. The elements are $\mathrm{Org}_{\text {goal }}, \mathrm{Sub} b_{\text {goal }}, A_{\text {ction }}$ and $T_{\text {ask }}$. As shown in Figure 1, every organization has Org goal that specifies the target that the members of organization try to achieve. This Org goal $_{\text {gal }}$ consists of a single $S u b_{\text {goal }}$ or several Sub goals to be achieved. However, $A_{c t i o n}$ is necessary required to achieve $S u b_{\text {goal }}$. This $A_{\text {ction }}$ comprises $T_{\text {ask }}$ in order to achieve $S u b_{\text {goal }} . T_{\text {ask }}$ is defined as a number of activities that are involve in $A_{\text {ction. }}$. These activities rely on

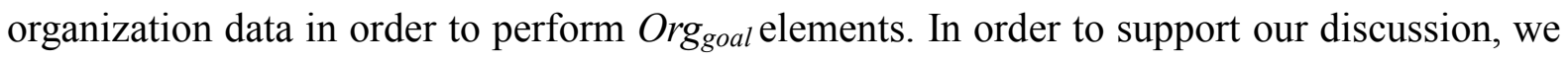
developed an organization ontology model based on $\mathrm{Org}_{\text {goal }}$ elements. The concept, based on the use of an ontology, has been studied previously in order to identify the relationships within the organization (Fox et al., 1996) but we improve this ontology using Org goal $_{\text {gelements. }}$

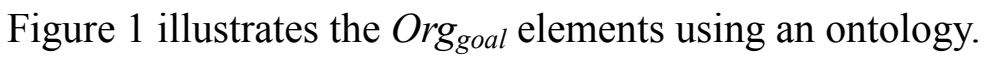




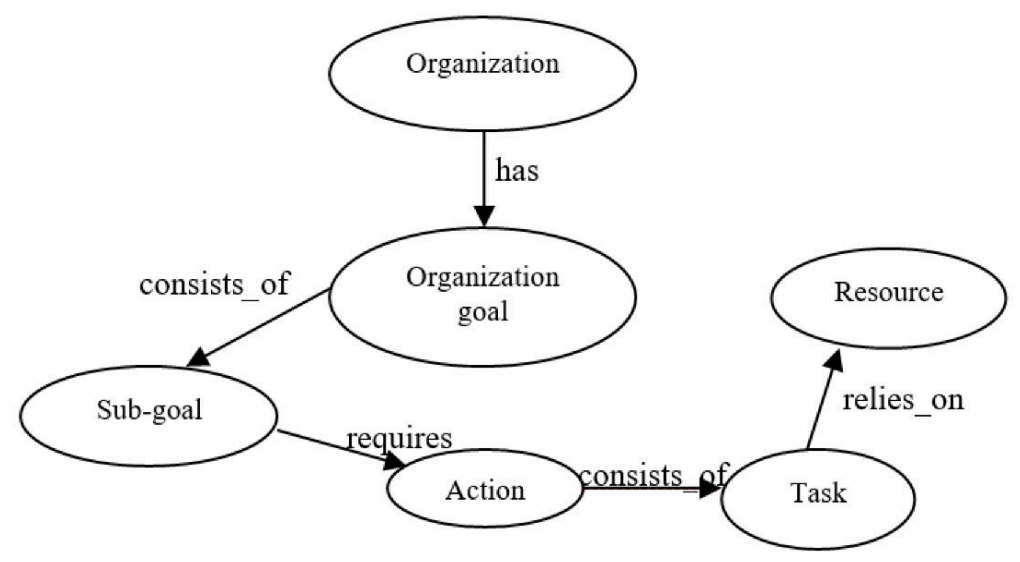

Figure 1. Org goal $_{\text {gom }}$ elemts

Note on Figure 1, each arrow " $\rightarrow$ " is defined as an operator function of Org goal $_{\text {glements }}$ within an organization. The following operators are use.

- has: Organization has Org goal $_{\text {g }}$

- consist_of: Org goal $_{\text {gonsist_of Sub goal }}$ to support Org goal $_{\text {go }}$.

- requires: Sub goal requires $A_{\text {ction }}$ with a number of activity that have been defined to achieve the goal.

- consist_of: $A_{\text {ction }}$ consist_of $T_{\text {ask }}$.

- relies_on: $T_{\text {ask }}$ relies_on resource as organization data.

The first circle in Figure 1 represents an organization which defined as a social group of people working in one scope of activity to achieve Org goal $_{\text {. An organization involves several }}$

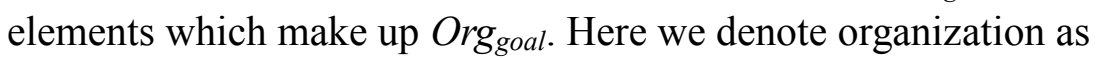

$$
\text { has }\left(O r g, \operatorname{Org}_{\text {goal }}\right)
$$

signifying that an organization has $\operatorname{Org}_{\text {goal }}$. Then, the second circle represents the $\operatorname{Org}_{\text {goal }}$. Goal is the higher and important achievement target in every organization. It consists of the process of identifying the aim of the organization. In order to achieve Org goal $_{\text {, an organization }}$ develops Sub goal. Taking an example in the context of the university library, if the main objective or goal is to Transform Student Lives Through Learning, then the Sub goal is to Create Pathways for Underrepresented Students and Substantially increase student enrolments. Here we denote $\mathrm{Org}_{\text {goal }}$ as

$$
\text { consist_of(Org goal, Sub goal) }
$$

signifying that $\mathrm{Org}_{\text {goal }}$ consists of $S u b_{\text {goal }}$. Follow by the third circle represents a $S u b_{\text {goal }}$ which defined as an out-come to achieve $\operatorname{Org}_{\text {goal }}$. It is very important for organizations to identify the $S u b_{\text {goal }}$ which are necessary to achieve in order to meet the $\operatorname{Org}_{\text {goal }}$. Sub goal is used as a platform by which to examine the organization's progress toward achieving its main goal. 


\section{Macrothink}

However, $A_{\text {ction }}$ is required to perform $S u b_{\text {goal }}$. Using the same example, if the main objective or goal is to Transform Student Lives Through Learning, then the Sub $b_{\text {goal }}$ is to Create Pathways for Underrepresented Students. Here $A_{\text {ction }}$ to achieve this goal is 'to work with relevant university staff to develop programs to support under-prepared students' or 'review and further develop the library website in order to create more effective gateways for diverse client groups'. Then, we denote $S u b_{\text {goal }}$ as

$$
\text { requires }\left(S u b_{\text {goal }}, A_{\text {ction }}\right)
$$

signifying that $S u b_{\text {goal }}$ requires $A_{\text {ction }}$. The fourth circle in Figure1 represents an $A_{\text {ction }} . A_{\text {ction }}$ is a set of activities performed by $T_{\text {ask }}$ in order to achieve $\operatorname{Org}_{\text {goal }}$. Here, $A_{\text {ction }}$ depends on $T_{a s k}$ and $T_{\text {ask }}$ is an activity in the achievement of $\mathrm{Org}_{\text {goal }}$. In addition, $A_{\text {ction }}$ provides a systematic organizational plan which must be followed to achieve its objectives. For example, if $A_{\text {ction }}$ is 'to work with relevant university staff to develop programs to support under-prepared students' then the possible $T_{\text {ask }}$ is to 'identify the student background in order to identify the most suitable program'. So, we denote $A_{\text {ction }}$ as

$$
\text { consist_of }\left(A_{\text {ction }}, T_{\text {ask }}\right)
$$

signifying that $A_{\text {ction }}$ consists of $T_{\text {ask }}$ in the progress toward $\operatorname{Org}_{\text {goal }}$. Another two circles represent $T_{a s k}$ and resources. $T_{a s k}$ is an activity performed in $A_{\text {ction }}$. However, as shown in Figure 1, $T_{\text {ask }}$ relies on resources, that is, organization data. Organization data is the most important asset of the organization in performing its daily activities. For example, if $T_{\text {ask }}$ is to 'identify the student background in order to identify the most suitable program' then the possible data is data on student background and data on student academic background. Here, we denote $T_{a s k}$ as

$$
\text { relies_on }\left(T_{a s k}, D_{\text {ata }}\right)
$$

signifying that $T_{\text {ask }}$ relies on data. In order to define the relationship in this model, the ontology model for the organization can be decomposed into an AND/OR goal tree. We demonstrate a simple example of goal tree model of $\mathrm{Org}_{\text {goal }}$ as in Figure 2. The model in Figure 2 demonstrated that $\operatorname{Org}_{\text {goal }}$ has two $S u b_{\text {goal }}$ which is $S u b_{\text {goal }} 1$ AND Sub goal 2. The, each of this $S u b_{\text {goal }}$ may involve $A_{\text {ction }} 1 \mathrm{OR} A_{\text {ction }} 2$.

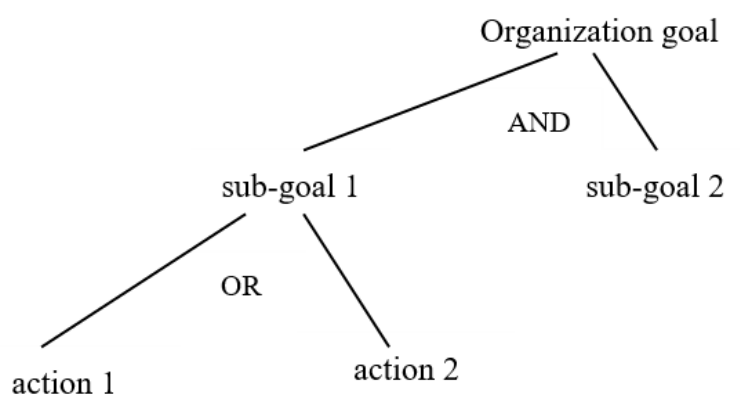

Figure 2. Goal tree model 


\section{Macrothink}

Note in Figure 2, if the relationship is 'AND' then $\operatorname{Org}_{\text {goal }}$ is represent as

$$
\operatorname{Org}_{\text {goal }}=\operatorname{consist}\left(\operatorname{Org}_{\text {goal }}, \text { Sub goal }_{\text {gol }}\right) \wedge \operatorname{consist}\left(\operatorname{Org}_{\text {goal }}, S_{u} b_{\text {goal }} 2\right) \text {. }
$$

This relationship is described as $\operatorname{Org}_{\text {goal }}$ consisting of $S u b_{\text {goal }} 1$ and $S u b_{\text {goal }} 2$ where " $\wedge$ " represents AND. If the relationship is 'OR' then

$$
\operatorname{Sub}_{\text {goal }} 1=\text { requires }\left(\operatorname{Sub} b_{\text {goal }}, A_{\text {ction }} 1\right) \vee \text { requires }\left(\operatorname{Sub} b_{\text {goal }}, A_{\text {ction }} 2\right) .
$$

The relationship is described as $S u b_{\text {goal }} 1$ requires $A_{\text {ction }} 1$ or $A_{\text {ction }} 2$ and "V" represent OR. As shown in Figure 2, $A_{\text {ction }} 2$ depends on $A_{\text {ction }} 1$ if $A_{\text {ction }} 1$ cannot be achieved then $A_{\text {ction }} 2$ is required, where " $\supset$ " is denoted as dependence.

$$
A_{\text {ction }}=S u b_{\text {goal }} 1\left(A_{\text {ction }} 1\right) \supset S u b_{\text {goal }} 1\left(A_{\text {ction }} 2\right)
$$

\subsubsection{Relationship Rule}

In order to identify the significant variables in the organization data, justifying the variables is very important in order to identify the dependent variables and independent variables between the $\operatorname{Org}_{\text {goal }}$ elements. In this paper, model evaluation is referring to three main variables rules. The relationships rules are.

Rule 1: Relationships between $\operatorname{Org}_{\text {goal }}$ and $S u b_{\text {goal }}$ then $\operatorname{Org}_{\text {goal }}$ is a dependent variable and $S u b_{\text {goal }}$ is an independent variable because $\operatorname{Org}_{\text {goal }}$ depends on $S u b_{\text {goal }}$.

Rule 2: Relationships between $S u b_{\text {goal }}$ and $A_{\text {ction }}$ then $S u b_{\text {goal }}$ is a dependent variable and $A_{\text {ction }}$ is an independent variable because $S u b_{\text {goal }}$ depends on $A_{\text {ction }}$.

Rule 3: Relationships between $A_{\text {ction }}$ and $T_{\text {ask }}$ then $A_{\text {ction }}$ is a dependent variable and $\mathrm{T}_{\text {ask }}$ is an independent variable because $A_{c t i o n}$ depends on $T_{a s k}$.

\subsection{Metric Model}

In this subsection, we develop a metric model. We develop this metric model based the $\mathrm{Org}_{\text {goal }}$ elements. In this model, we clarify our metric based on metric requirement and metric analysis. Metric requirement is a metric design of what needs to be accomplished during the metric process. We identify two variables in metric requirements which are verifiable and measure. In this metric, verifiable is defined as a set of data that been agreed for converting process into measure. Thus, metric must have the capability of being verified and meets the regulatory concept. Meanwhile, measure is defined as characteristics in a numerical or nominal form. In this case, metric must have the ability to integrate over all possible processes, algorithms or functions. Metric analysis is defined as a requirement that must be fulfilled in metric development. We identify three variables in metric analysis: control, communication and improvement. In this metric, control is the ability of metrics to evaluate and control the source they are measuring. Communication is the ability of metrics to communicate externally and internally for the purpose of control. Improvement is the ability to identify the gaps for improvement. The structure of the metric model is shown in Figure 3. 


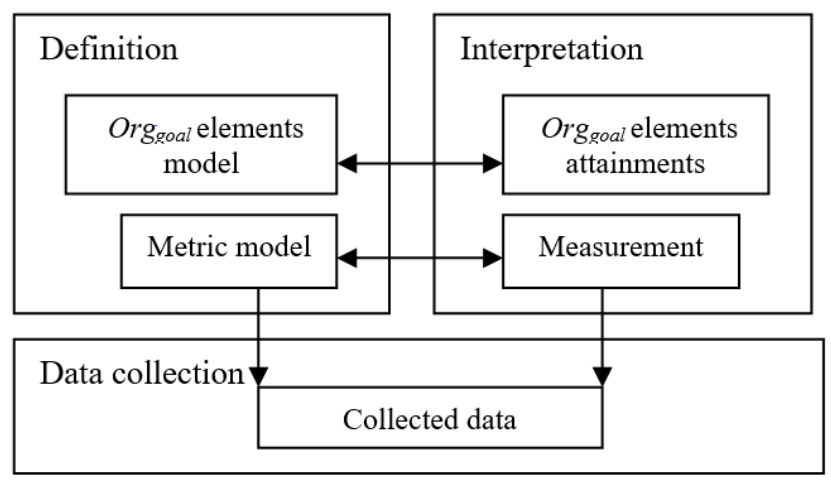

Figure 3. Stages of the metric model

Figure 3 illustrates the process regarding the metric model. During the definition stage, $\mathrm{Org}_{\text {goal }}$ elements model is develop based on ontology. Then, we defined metric model that fit with the ontology model. In the interpretation stage, this is the measurement which is based on data collection. This is a model we develop in this paper in an effort to evaluate organization data which will be in line with $\operatorname{Org}_{\text {goal }}$. This process has been discussed in (Soligen \& Berghout, 1999) but the authors discussed the process in relation to software improvement such as GQM.

\subsubsection{Basic Terminologies}

In this subsection, we introduce terminologies for metric model. The terminologies involve the definition of metric scale and the metric rules.

Metric model is defined based on a scale $(1 \rightarrow 7)$ : low (0-2), fair (3-5) and important (6-7). This scale is important in identifying the value of organization data between $\mathrm{Org}_{\text {goal }}$ elements.

The model evaluates the value of organization data in based on two main rules: if the value of organization data is $\leq 2$, then organization data are not important and if the value of organization data is $\geq 3$, then the organization data are important and needs to be considered during the decision-making process.

It is important for the metric to verify both the quantitative and qualitative measures of organization data, because as the volume of organizational data increase, the metric is able to refine the data.

\section{Case Study}

In this section, we present a case study to test our concept. The aims of this case study are to develop an ontology model based on real scenario and to evaluate organization data based on metric model. In this case study, we apply data from La Trobe University Library.

\subsection{University and Library Ontology Model}

The model in this case study discussed the relationship between library $A_{\text {ction }}$ and university $A_{\text {ction }}$ in relation with university $S u b_{\text {goal }}$ and main goal (see www.latrobe.edu.au/library). Thus, 
this relationship is concluded as between $S u b_{\text {goal }}$ and $A_{\text {ction }}$ (see Section 3.1.2).

The university's goal is to 'Transform the lives of students and communities through learning and knowledge'. This goal consists of a $S u b_{\text {goal }}$ which is to 'create new and useful knowledge'. Next, the university requires several $A_{\text {ction }}$ to achieve this $S u b_{\text {goal }}$. This scenario necessitates looking at the library's $A_{\text {ction }}$ that supports the university's $A_{\text {ction }}$, the university's $S u b_{\text {goal }}$ and the university's goal.

The first university $A_{\text {ction }}$ to support the university $S u b_{\text {goal }}$ is to 'increase the quantity and quality of research activity'. This university $A_{\text {ction }}$ is supported by the library's $A_{\text {ction }}$ such as 'establish research data management services', 'investigate the provision of a bibliographic citation reporting service, promote the new postgraduate study room in library Melbourne campus' and 'extend and promote digital object management services'. The second university $A_{\text {ction }}$ to support the university $S u b_{\text {goal }}$ is to 'develop knowledge exchange programs'. In order to achieve this university $A_{\text {ction, }}$, the library has developed $A_{\text {ction }}$ to 'develop strategies for increasing the number of full text open access research output in the repository'; hence, this Library $A_{\text {ction }}$ is important in increasing the impact and reputation of La Trobe University's research. Another library $A_{c t i o n}$ is to 'enhance the profile and maximise the use of library special collection'. This has been done through the promotion, digitisation and collection acquisition. The last university $A_{\text {ction }}$ to support the university $S u b_{\text {goal }}$ is to 'produce more excellently trained research graduates'. The university's library has developed an $A_{\text {ction }}$ to assist this university $A_{\text {ction, }}$, this being to 'develop a research gateway on the library website for academic staff and postgraduate students' and to 'provide targeted outreach services for academic staff and postgraduate students' that is tailored to research skills training.

The above example gives a complete picture of $\mathrm{Org}_{\text {goal }}, \mathrm{Su} \mathrm{b}_{\text {goal }}$ and $A_{\text {ction }}$ within the university and library environment. Figure 4 shows the entire relationship based on the ontology. In this concept, $A_{\text {ction }}$ consists of $T_{\text {ask }}$ and $T_{\text {ask }}$ relies on data to perform $\operatorname{Org}_{\text {goal }}$. Taking one university and library $A_{\text {ction }}$ as an example, the university $A_{\text {ction }}$ is to 'produce more excellently trained research graduates' and the library $A_{\text {ction }}$ that consists of the $T_{\text {ask }}$ is to 'develop a research gateway on the library website for academic staff and postgraduate student'. The data that the library required in the achievement of these $T_{a s k}$ and $A_{\text {ction }}$ is 'data on previous research year', 'data on research area' and 'data on research publication'. These data help the library to develop a research gateway within the website. Hence, users can rely on this data to perform their research. Figure 4 illustrates the ontology relationship in this case study. 


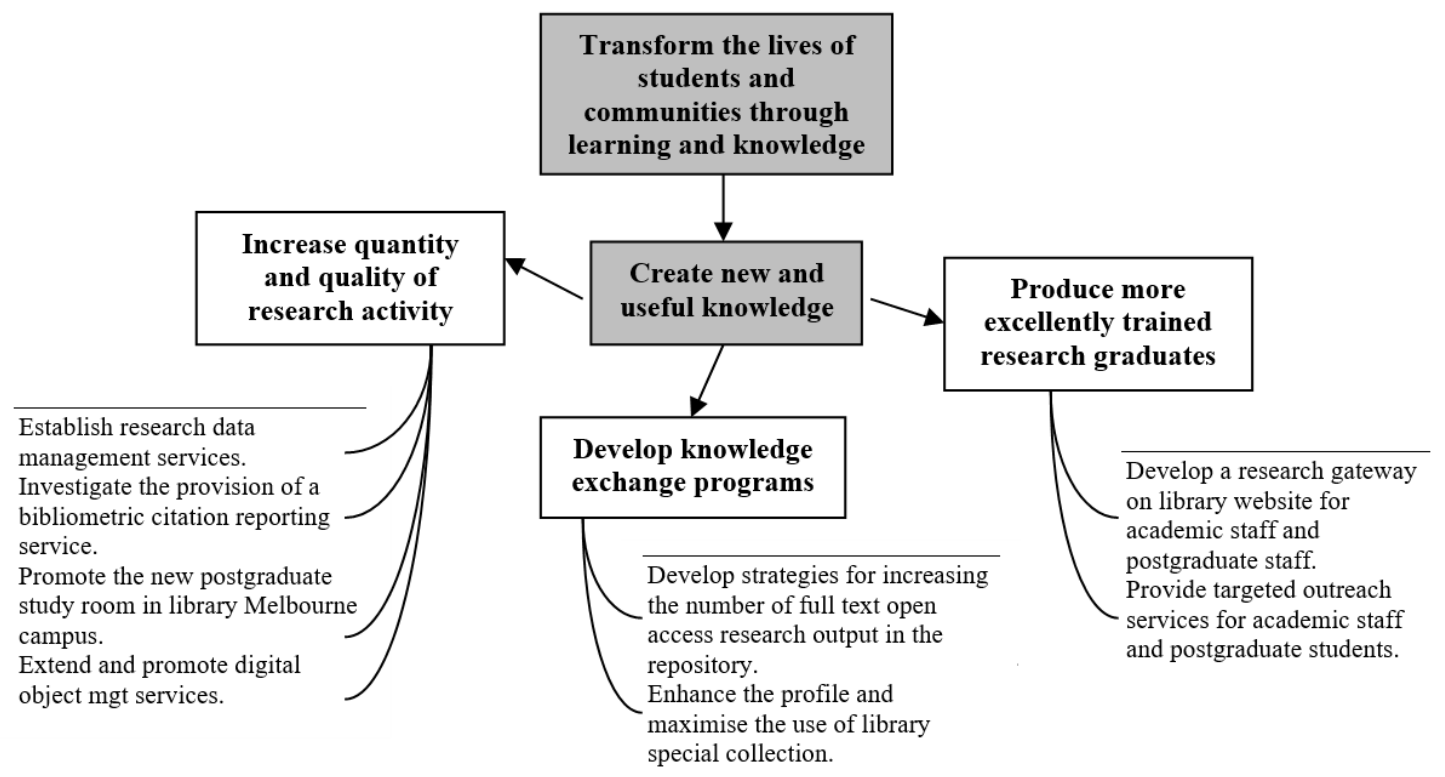

Figure 4. Ontology relationship between goal (university goal), sub-goal (university sub-goal) and action (university action and library action)

\subsection{Metric Measurement}

In this paper, we measured the extent of the metric model that is vital to identify the value of the library data that are important in the achievement of the library $A_{\text {ction }}$ and the university goal. Using real library data, the library has already interpreted these data as 1 being low and 7 being high. However, we improved this interpretation by using our definition based on metric $(1 \rightarrow 7)$ : low $(0-2)$, fair (3-5) and important (6-7). Using this interpretation, we summarized the value of library data based on metric rules. If the value of library data is $\leq 2$ then the data are not important and if the value of library data is $\geq 3$ then the data are important and need to be considered during the decision-making process.

\subsubsection{Evaluation Steps}

In this case study, data were obtained from the La Trobe University Library (see http://www.lib.latrobe.edu.au/about/surveys.php). In order for library to achieve its goal in relation to the university goal, library is evaluated based on library's performance and importance. In this library survey, library data were collected based on users perception of library's performance and importance. In this subsection, we improve the library's interpretation of data using a metric. In this case study, we do not apply any data analysis but we used real survey data from the library, as we described as being important for the library $A_{\text {ction }}$ in the achievement of the university's goal.

\subsubsection{Data Selection}

In this paper, we obtained data from the library's website but the library data were too vast. In order to implement our concept, we select data that are suitable to support the library's 
importance and performance. At this stage, the library data were selected randomly because the library had already interpreted these data based on the Insync Survey (Note 1). Thus, we used these library data in an effort to test our concept. Selected library are shown in Table 2 and Table 3.

\subsubsection{Results}

Table 2 displays all the results based on what users believe to be important for the library. The results concluded that users believe that all the aspects in Table 2 are important. The results show that these library data are important for the library to achieve library $A_{\text {ction }}$ in relation to achieve university's goal.

Table 2. What users believe to be important for the library

\begin{tabular}{|c|c|c|c|}
\hline Important & Mean & Important & Mean \\
\hline $\begin{array}{l}\text { Online resource (eg e-journals, database, } \\
\text { e-books) meet my learning and research needs }\end{array}$ & 6.54 & $\begin{array}{l}\text { Library staff treat me fairly and } \\
\text { without discrimination* }\end{array}$ & 6.44 \\
\hline $\begin{array}{l}\text { Library staff provide accurate answers to my } \\
\text { enquiries* }\end{array}$ & 6.51 & $\begin{array}{l}\text { Library staff are readily available to } \\
\text { assist me* }\end{array}$ & 6.43 \\
\hline $\begin{array}{l}\text { Library staff are approachable and } \\
\text { helpful* }\end{array}$ & 6.49 & The library web site is easy to use & 6.42 \\
\hline $\begin{array}{l}\text { I can get wireless access in the } \\
\text { library when I need to* }\end{array}$ & 6.46 & $\begin{array}{l}\text { The items I'm looking for on the } \\
\text { library shelves are usually there }\end{array}$ & 6.41 \\
\hline $\begin{array}{l}\text { When I am away from campus I can } \\
\text { access the library resources and } \\
\text { services I need* }\end{array}$ & 6.44 & The library catalogue is easy to use & 6.40 \\
\hline
\end{tabular}

Note. *The same variables as Table 3.

Table 3. How users believe the library is performing

\begin{tabular}{llll}
\hline Performance & Mean & Performance & Mean \\
\hline $\begin{array}{l}\text { Library staff treat me fairly and } \\
\text { without discrimination* }\end{array}$ & 6.19 & The library web site is easy to use & 5.64 \\
$\begin{array}{l}\text { Library staff provide accurate answers to my } \\
\text { enquiries* }\end{array}$ & 5.85 & $\begin{array}{l}\text { I can get wireless access in the } \\
\text { library when I need to* }\end{array}$ & 5.63 \\
$\begin{array}{l}\text { Library staff are approachable and } \\
\text { helpful* }\end{array}$ & 5.84 & $\begin{array}{l}\text { Library staff are readily available to } \\
\text { assist me* }\end{array}$ & 5.63 \\
$\begin{array}{l}\text { Self Service (e.g., self-check loans, } \\
\text { requests, renewals, holds) meets my } \\
\text { needs }\end{array}$ & 5.81 & $\begin{array}{l}\text { Books and articles I have requested } \\
\text { from other libraries and campuses are } \\
\text { delivered promptly }\end{array}$ & 5.62 \\
$\begin{array}{l}\text { When I am away from campus I can } \\
\text { access the library resources and }\end{array}$ & 5.69 & Opening hours meet my needs \\
services I need*
\end{tabular}

Note. ${ }^{*}$ The same variables as Table 2. 


\section{Macrothink}

In Table 3, we present the results based on how users view the library's performance. Based from the results in Table 3, we can conclude that the library is performed in order to fulfil user's satisfaction. The results show that these library data are important for library to evaluate its performance in relation to achieve library $A_{\text {ction }}$.

Tables 2 and 3 displays all the significant correlations between the same variables and these correlations are shown in Table 4 . The results in Table 4 discussed the correlations between dependent variable and independent variable. In this case, we represent dependent variable as $y$ and independent variable as $x$. The results show that user's perception on library's importance and performance is high. These finding indicate the reliability of the of library's importance and performance in relation to meeting the university's goal.

Table 4. Variables

\begin{tabular}{lll}
\hline Variables & $\begin{array}{l}\text { Important } \\
\left(x_{1}\right)\end{array}$ & $\begin{array}{l}\text { Performance } \\
\left(x_{2}\right)\end{array}$ \\
$(y)$ & 6.54 & 5.86 \\
\hline Library staff provide accurate answers to my enquiries & 6.49 & 5.84 \\
Library staff are approachable and helpful & 6.46 & 5.63 \\
I can get wireless access in the Library when I need to & 6.44 & 5.69 \\
When I am away from campus I can access the Library resources and services I & & 6.19 \\
need & 6.44 & 5.63 \\
Library staff treat me fairly and without discrimination & 6.43 & \\
Library staff are readily available to assist me & & 5 \\
\hline
\end{tabular}

The relationship between the correlations variables in Table 4 are developed as shown in Figure 5. It can be concluded that the relationship between variables are important in order to verify the library data that are important in the achievement of the university's goal.

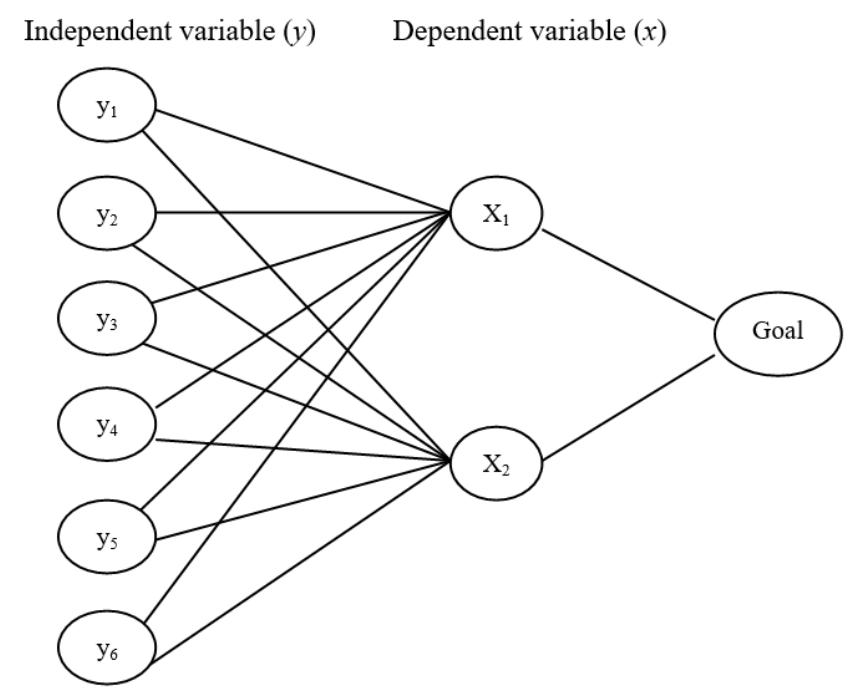

Figure 5. Variables diagram 
In the context of data evaluation between organization data, data analysis is very important in order to measure dependent and independent variable. This process is important to identify the set of components which is known as latent vectors and these vectors perform an immediate decomposition between dependent variables and independent variables. It explains the covariance between dependent variable and independent variable so the focus is the step to estimate organization data within variables.

\section{Discussion}

Organizations are accumulating vast amounts of data due to the implementation of information system that make it easier to collect and store organization data. Entrepreneurs require organization data to assist them to make decisions and they need to identify valid and current organization data within vast amounts of organization data to support their decision making. The discussion for this paper is justified based on two main processes: model development and metric development.

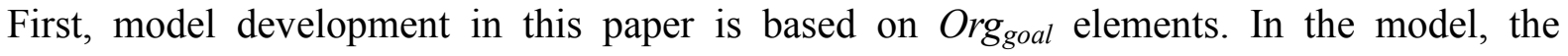
relationship among Org goal $_{\text {gal }}$ elements is very important in an effort to evaluate organization data in relation to meeting the $\mathrm{Org}_{\text {goal }}$. In order to achieve this, an ontology is applied to create the relationship among $\operatorname{Org}_{\text {goal }}$ elements. The relationship shows that $\operatorname{Org}_{\text {goal }}$ consists of $S u b_{\text {goal }}$ and $S u b_{\text {goal }}$ require $A_{\text {ction. }}$. Then $A_{\text {ction }}$ consists of $T_{\text {ask }}$ to perform $S u b_{\text {goal }}$. The relationship is very important in order to identify the variables aspect among these Org goal $_{\text {gal }}$ elements. These are the $\operatorname{Org}_{\text {goal }}$ elements that we have identified in our model.

Second, metric development in this paper is proposed to evaluate the value of organization

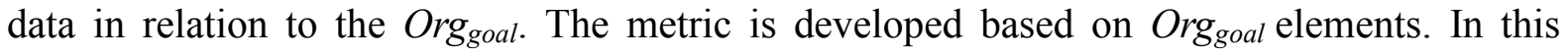
metric, we set a scale and this scale is used to evaluate organization data and to identify the value of organization data. On the other hand, we identified rules for the model to evaluate the value of organization data.

In the case study, we used data from La Trobe University Library in an effort to support the university's goal. However, the library data in this case study has already been interpreted but we expanded this interpretation using our metric model. The relationship in the case study is concluded as between $S u b_{\text {goal }}$ and $A_{\text {ction }}$ (see Section 3.1.2).

Results from the case study examined the discussion between $\operatorname{Org}_{\text {goal }}$ elements in the context of the library goals and the university's goal. In the case study, a relationship is developed between library $A_{c t i o n}$ and university $A_{\text {ction }}$ in relation to achieve the university's goal. At the same time, library data from the case study identified the correlations between Org $_{\text {goal }}$ elements in the context of the library. In other words, the model identified the correlations between dependent variables and independent variables between the library $A_{\text {ction }}$ and university $A_{\text {ction }}$ in relation to meeting the university's goal. In the case study, library $A_{\text {ction }}$ is performed in line with university $A_{\text {ction }}$, which means that university $A_{\text {ction }}$ depends on library $A_{\text {ction }}$ to achieve university's goal. Therefore, we concluded university $A_{\text {ction }}$ is a dependent variable and library $A_{\text {ction }}$ is an independent variable. At the same time, the results show all the significant correlations between the same variables (see Table 4). These correlations 
significantly discussed the important of data evaluation between organization which conclude that data analysis is very important in order to measure dependent and independent variable.

\section{Conclusion and Future Work}

The aim of this paper was to develop a model based on Org goal $_{\text {elements and ontology as a }}$ tool to evaluate the quality of the organization data in relation to achieve $\mathrm{Org}_{\text {goal }}$. This model is important in measuring the extent to which organization data are consistent with the organization goal. Data from the internal and external organization environment is analysed to assist the process of decision making in an effort to achieve $\operatorname{Org}_{\text {goal }}$. In Section 1 of this paper, we discussed the concept. In Section 2, we discussed existing literature. In Section 3, we developed a model based on ontology and we developed a metric model. In Section 4, we applied a case study. In this section, we developed an ontology model in the context of library's and university's goal. Then, we evaluated library data using our metric model. In the case study, we identified independent variables and dependent variables. We concluded that these variables are important in order to identify the dependency within the huge amount of library data.

The main limitations in this paper include the metric model in organization data interpretation, the ontology model based on Org gaal $_{\text {gal }}$ elements and the small amount of library data in our case study. In order to eliminate these limitations, further works are necessary. Thus, one

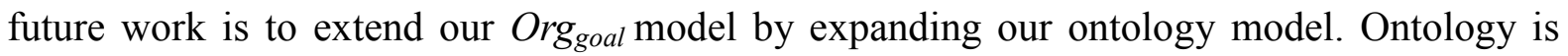
important to improve the relationship between $\operatorname{Org}_{\text {goal }}$ elements. Other future work is to expand the metric model that we have developed in order to interpret future organization data to support $\mathrm{Org}_{\text {goal }}$. In this paper, we used library data and we improved the interpretation of library data using our metric. However, in the future, we will apply large organization data in an effort to implement our metric. Therefore, it is important to develop a metric that can fit to any organization data.

In the nutshell, the main contribution of this paper is to propose a model that seeks to support the evaluation of organization data based on Org goal $_{\text {gal }}$ elements. As a result, the model development needs to deal with organization data inconsistencies, changes and gaps.

\section{References}

Albino, V., Garavelli, A. C., \& Schiuma, G. (2001). A metric for measuring knowledge codification in organisation learning. Technovation, 21(7), 413-422. https://doi.org/10.1016/S0166-4972(00)00058-4

Ardimento, P., Maria, T. B., Danilo, C., \& Giuseppe, V. (2006). Assessing multiview framework (MF) comprehensibility and efficiency: A replicated experiment. Information and Software Technology, 48(5), 313-322. https://doi.org/10.1016/j.infsof.2005.09.010

Barlas, Y., \& Hakan, Y. (2006). Goal setting, evaluation, learning and revision: A dynamic modeling approach. Evaluation and Program Planning, 29(1), 79-87. https://doi.org/10.1016/j.evalprogplan.2005.08.003

Basili, V. R., \& David, M. W. (1984). A methodology for collecting valid software 
engineering data. IEEE Transaction on Software Engineering, 10(6), 728-738. https://doi.org/10.1109/TSE.1984.5010301

Ceresia, F. (2011). A model of goal dynamic in technology-based organizations. Journal of Engineering and Technology Management, 28(1-2), 49-76. https://doi.org/10.1016/j.jengtecman.2010.12.004

Christensen, C. M., \& Bower, J. L. (1996). Customer power, strategic investment and the failure of leading firms. Strategic Management Journal, 17(3), 197-218. https://doi.org/10.1002/(SICI)1097-0266(199603)17:3<197::AID-SMJ804>3.0.CO;2-U

Ebert, C., \& Ivan, M. (1997). Metrics for quality analysis and improvement of object-oriented software. Information and Software Technology, 39(7), 497-509. https://doi.org/10.1016/S0950-5849(97)00005-0

England, G. W., \& Raymond, L. (1973). Organization size as an influence on perceived organizational goals: A comparative study among American, Japanese, and Korean managers. Organizational Behavior and Human Performance, 9(1), 48-58. https://doi.org/10.1016/0030-5073(73)90036-6

Fox, M. S., Mihai, B., \& Michael, G. (1996). An organisation ontology for enterprise modeling: Preliminary concepts for linking structure and behaviour. Computers in Industry, 29(1-2), 123-134. https://doi.org/10.1016/0166-3615(95)00079-8

Gruber, M. (2007). Uncovering the value of planning in new venture creation: A process and contigency perspective. Journal of Business Venturing, 22(6), 782-807. https://doi.org/10.1016/j.jbusvent.2006.07.001

Hall, D. T., \& Francine, S. H. (1976). The relationship between goals, performance, success, self-image and involvement under different organization climates. Journal of Vocational Behavior, 9(3), 267-278. https://doi.org/10.1016/0001-8791(76)90055-5

Han, K. H., \& Jun, W. P. (2009). Process-centered knowledge model and enterprise ontology for the development of knowledge management system. Expert Systems with Applications, 36(4), 7441-7447. https://doi.org/10.1016/j.eswa.2008.09.031

Hevner, A. R. (1997). Phase containment metrics for software quality measurement. Information and Software Technology, 39(13), 867-877. https://doi.org/10.1016/S0950-5849(97)00050-5

Huang, N., \& ShiHan, D. (2008). Ontology-based enterprise knowledge integration. Robotics and Computer-Integrated Manufacturing, 24(4), 562-571. https://doi.org/10.1016/j.rcim.2007.07.007

Jimeno-Yepes, A., Rafael, B.-L., \& Dietrich, R.-S. (2010). Information Processing and Management. Information Processing and Management, 46(4), 426-435. https://doi.org/10.1016/j.ipm.2009.05.008

Kang, D., Jeongsoo, L., Sungchul, C., \& Kwangsoo, K. (2010a). An ontology-based 
Enterprise Architecture. Expert Systems with Applications, 37(2), 1456-1464. https://doi.org/10.1016/j.eswa.2009.06.073

Kang, D., Jeongsoo, L., \& Kwangsoo, K. (2010b). Alignment of Business Enterprise Architectures using fact-based ontologies. Expert Systems with Applications, 37(4), 3271-3283. https://doi.org/10.1016/j.eswa.2009.09.052

Lee, Y.-C., Tzung-Pei, H., \& Tien-Chin, W. (2008). Multi-level fuzzy mining with multiple minimum supports. Expert Systems with Applications, 34(1), 459-468. https://doi.org/10.1016/j.eswa.2006.09.011

Lusk, E. J., \& Bruce, L. O. (1974). Perceived importance of "social goals" in business organizations. The International Journal of management Science, 2(4), 553-556. https://doi.org/10.1016/0305-0483(74)90072-3

Ordonez, C., \& Javier, G.-G. (2008). Referential integrity quality metrics. Decision Support Systems, 44(2), 495-508. https://doi.org/10.1016/j.dss.2007.06.004

Petkova, V. T., Peter, C. S., \& Aarnout, C. B. (2000). The use of quality metrics in service centres. International Journal of Production Economics, 67(1), 27-36. https://doi.org/10.1016/S0925-5273(00)00007-4

Seng, J.-L., \&Chen, T. C. (2010). An analytic approach to select data mining for business decision. Expert Systems with Applications, 37(12), 8042-8057. https://doi.org/10.1016/j.eswa.2010.05.083

Soligen, R. v., \& Egon, B. (1999). The Goal/Question/Metric Method: A practical guide for quality improvement software development. London: The McGraw-Hill Companies.

Song, M. K., Podoynitsyna, H., Van, d. B., \& Halman, J. I. M. (2008). Success factors in new ventures: A meta-analysis. Journal of Product Innovation Management, 25(1), 7-27. https://doi.org/10.1111/j.1540-5885.2007.00280.x

Song, M., Tang, W., \& Mark, E. P. (2010). Do market information processes improve new venture performance? Journal of Business Venturing, 25(6), 556-568. https://doi.org/10.1016/j.jbusvent.2009.03.003

\section{Notes}

Note 1. Insync Surveys ensures libraries can measure performance against each other that help libraries to develop the highest possible standards of service for library users.

\section{Copyrights}

Copyright for this article is retained by the author(s), with first publication rights granted to the journal.

This is an open-access article distributed under the terms and conditions of the Creative Commons Attribution license (http://creativecommons.org/licenses/by/4.0/). 